Article

\title{
Chemical Constituents of Supercritical Extracts from Alpinia officinarum and the Feeding Deterrent Activity against Tribolium castaneum
}

\author{
Mintong Xin ${ }^{1}$, Shanshan Guo ${ }^{1}$, Wenjuan Zhang ${ }^{1}$, Zhufeng Geng ${ }^{1,2}$, Junyu Liang ${ }^{1}$, \\ Shushan Du ${ }^{1, *}$, Zhiwei Deng ${ }^{2}$ and Yongyan Wang ${ }^{1}$ \\ 1 Beijing Key Laboratory of Traditional Chinese Medicine Protection and Utilization, \\ Faculty of Geographical Science, Beijing Normal University, Beijing 100875, China; \\ 201231190019@mail.bnu.edu.cn (M.X.); guoshanshan@mail.bnu.edu.cn (S.G.); \\ zwj0729@mail.bnu.edu.cn (W.Z.); gengzhufeng@bnu.edu.cn (Z.G.); liangjunyu@nwnu.edu.cn (J.L.); \\ narcissus09@126.com (Y.W.) \\ 2 Analytical and Testing Center, Beijing Normal University, Beijing 100875, China; dengzw@bnu.edu.cn \\ * Correspondence: dushushan@bnu.edu.cn; Tel./Fax: +86-10-6220-8022
}

Academic Editor: Derek J. McPhee

Received: 15 March 2017; Accepted: 15 April 2017; Published: 18 April 2017

\begin{abstract}
Alpinia officinarum has been confirmed to possess bioactivities against some pests. In this work, a sample was obtained from A. officinarum rhizomes by supercritical fluid $\mathrm{CO}_{2}$ extraction (SFE). According to GC-MS analysis, the main chemical components for SFE-sample included benzylacetone (26.77\%), 1,7-diphenyl-5-hydroxy-3-heptanone (17.78\%), guaiacylacetone $(10.03 \%)$ and benzenepropanal (7.42\%). The essential oil of $A$. officinarum rhizomes $\left(\mathrm{LD}_{50}=20.71 \mu \mathrm{g} / \mathrm{adult}\right)$ exhibited more contact toxicity than SFE extract $\left(\mathrm{LD}_{50}=82.72 \mu \mathrm{g} /\right.$ adult $)$ against Tribolium castaneum. From SFE extracts, one new compound, 1-phenyl-4-(16,17-dimethyl-9,13-octadiene)-5-isopentenyl-7(4"-methoxyl-3"-hydroxyl-phenyl)-3-heptanone (3), together with five known compounds identified as 5-hydroxy-1,7-diphenyl-3-heptanone (1), 1,7-diphenyl-4-hepten-3-one (2), galangin (4), galangin-3-methyl ether (5) and pinocembrin (6), were isolated and their feeding deterrent activities against $T$. castaneum adults were assessed. It was found that compounds 1-6 had feeding deterrent activities against $T$. castaneum with feeding deterrent indices of $18.21 \%, 18.94 \%, 19.79 \%$, $26.99 \%, 20.34 \%$, and $35.81 \%$, respectively, at the concentration of $1500 \mathrm{ppm}$. Hence, the essential oil and SFE extracts/compounds of A. officinarum rhizomes represent promising alternatives in the control of T. castaneum adults.
\end{abstract}

Keywords: Alpinia officinarum; 1-phenyl-4-(16,17-dimethyl-9,13-octadiene)-5-isopentenyl-7-(4"methoxyl-3"-hydroxyl-phenyl)-3-heptanone; Tribolium castaneum; contact toxicity; feeding deterrent activity

\section{Introduction}

It is estimated that direct and indirect losses of grains and grain-based products caused by stored-product insects range from about $10 \%$ in temperate regions to almost $50 \%$ in humid tropical areas [1]. The red flour beetle, Tribolium castaneum (Herbst), a big threat to stored products, has caused serious damage to crop stores throughout the world, including reducing the quantity and quality of the food economy [2-5]. Several chemical insecticides have been used to protect stored products from insect infestation. Although effective, their repeated use has led to the resurgence and resistance of these insects, resulted in the development of environmental pollution, and produced undesirable effects on non-targeted animals [6,7]. In premodern China, many medicinal herbs and spices were 
used to control storage pests [8]. Antagonistic storage is a traditional Chinese medicinal material conservation method that has also been used for medicinal materials that have special volatile odors to prevent other Chinese medicinal materials from suffering insect attacks [9]. This method has been in use for a long time, playing an important role in the ecological protection and utilization of traditional Chinese medicine resources [10]. In order to develop this traditional method of prevention and to control storage pests, this study established a screening program and focus on the volatile substances due to their major role in the antagonistic storage process.

Alpinia officinarum Hance (Zingiberaceae), commonly known as lesser galangal, is an important plant from the ginger family that originates in southern China and is cultivated in Southeast Asia [11]. Its rhizomes, which have a strong aromatic odour, have been used as Chinese folk medicine (usually called "Gao-liang-jiang") for decades [12]. Numerous studies reported that A. officinarum possesses anti-inflammatory, anticancer, antibacterial, antifungal, antihyperlipidemic, antiemetic, and diuretic properties [11-13]. As a traditional Chinese material that is usually used for antagonistic storage to prevent insects [14], A. officinarum (especially its essential oil) has been confirmed to possess bioactivities against Sitophilus zeamais, T. castaneum [15], Liposcelis bostrychophila [16], Lasioderma serricorne [17], Coptotermes gestroi, Coptotermes curvignathus, and other pests [18].

Previous research has already investigated the essential oil of $A$. officinarum extracted by hydrodistillation (HD) against L. serricorne [17]. Compare with $\mathrm{HD}$, the supercritical fluid $\mathrm{CO}_{2}$ extraction (SFE) is an environmentally benign and mild method that may reduce thermal degradation and retain the components without any change. In addition, this method has an economic advantage because it is much faster than other liquids extraction $[19,20]$. Researchers have investigated the composition of $A$. officinarum by SFE and detected some diarylheptanoids [21]. However, there are few reports available on the bioactivities of the oil extracts and its individual compounds from $A$. officinarum obtained by SFE against T. castaneum. The objectives of this study were to (i) compare the contact toxicity of the essential oil and SFE extracts of $A$. officinarum against T. castaneum adults; (ii) isolate compounds from SFE section of A. officinarum; and (iii) test feeding deterrent activity of the isolated compounds against T. castaneum.

\section{Results and Discussion}

\subsection{Chemical Compounds}

The yields of $A$. officinarum samples obtained by HD and SFE were $0.62 \%(v / w)$ [17] and $11.1 \%$ $(v / w)$, respectively. Comparing the two methods, the yield of SFE-sample is much higher than the essential oil because supercritical fluids diffusivities are much faster than in liquids. In addition, due to the lack of surface tension and negligible viscosities compared to liquids, the solvent can penetrate into the matrix to a degree inaccessible to liquids [22]. As shown in Table 1, the results of GC-MS analysis between essential oil and SFE-sample were different. Examination of SFE-sample by GC-MS analysis revealed the presence of 30 components, accounting for $68.90 \%$ of the total. The main compounds were identified as benzylacetone (26.77\%), 1,7-diphenyl-5-hydroxy-3-heptanone (17.78\%), guaiacylacetone $(10.03 \%)$, and benzenepropanal $(7.42 \%)$. In the case of essential oil, the GC-MS analysis revealed 31 components representing 69.36\%, and the major compounds were identified as 1,8-cineole (51.46\%), $\alpha$-terpineol (9.85\%), and $\delta$-cadinene isomers (5.44\%). Most of the main compounds in the SFE sample (1,7-diphenyl-5-hydroxy-3-heptanone, guaiacylacetone, and benzenepropanal) were not identified in the essential oil. This may be because some compounds with low boiling points were removed or because some compounds sensitive to heat changed under a relative high temperature during the long extraction time. In addition, the SFE method was performed using low polarity $\mathrm{CO}_{2}$ : thus the low polarity constituent (usually with the carbanyl and aldehyde groups) such as aldehydes, ketones, esters, and ethers were more likely to be obtained. Previous research reported the comparison among three $A$. officinarum samples extracted by HD, solvent extraction, and ultrasonic-assisted extraction (UAE) [23]. It was found that the UAE method of obtaining chemical constitutes of A. officinarum oil 
was more efficiency than other two methods, more time saving, and more energy efficient, but the oil quality was poorer due to the use of organic solvents that were hard to remove. Therefore, extraction methods must be selected according to the functional requirements of products.

Table 1. Chemical components of two samples from A. officinarum rhizomes.

\begin{tabular}{|c|c|c|c|c|c|}
\hline \multirow{2}{*}{ Compounds } & \multirow{2}{*}{$\begin{array}{l}\text { Molecular } \\
\text { Formula }\end{array}$} & \multirow{2}{*}{$\mathbf{R I}^{\mathbf{a}}$} & \multicolumn{2}{|c|}{ Relative Content } & \multirow{2}{*}{$\begin{array}{c}\text { Identification } \\
\text { Methods }^{c}\end{array}$} \\
\hline & & & Essential Oil $^{b}$ & SFE Extracts & \\
\hline$\alpha$-Pinene & $\mathrm{C}_{10} \mathrm{H}_{16}$ & 940 & 3.26 & - & RI, MS \\
\hline Camphene & $\mathrm{C}_{10} \mathrm{H}_{16}$ & 956 & 4.57 & - & RI, MS, Co \\
\hline Sabinene & $\mathrm{C}_{10} \mathrm{H}_{16}$ & 976 & 3.65 & 0.14 & RI, MS, Co \\
\hline$\beta$-Pinene & $\mathrm{C}_{10} \mathrm{H}_{16}$ & 978 & - & 0.09 & RI, MS, Co \\
\hline$\alpha$-Phellandrene & $\mathrm{C}_{10} \mathrm{H}_{16}$ & 1005 & 0.49 & 0.13 & RI, MS \\
\hline$\beta$-Phellandrene & $\mathrm{C}_{10} \mathrm{H}_{16}$ & 1026 & 3.42 & - & RI, MS \\
\hline 1,8-Cineole & $\mathrm{C}_{10} \mathrm{H}_{18} \mathrm{O}$ & 1031 & 51.64 & 0.80 & RI, MS, Co \\
\hline$\gamma$-Terpinene & $\mathrm{C}_{10} \mathrm{H}_{16}$ & 1057 & 0.67 & 0.19 & RI, MS, Co \\
\hline Isoterpinolene & $\mathrm{C}_{10} \mathrm{H}_{16}$ & 1085 & 0.23 & 0.13 & RI, MS \\
\hline Linalool & $\mathrm{C}_{10} \mathrm{H}_{18} \mathrm{O}$ & 1099 & 0.28 & 0.06 & RI, MS \\
\hline Camphor & $\mathrm{C}_{10} \mathrm{H}_{18} \mathrm{O}$ & 1145 & 1.84 & 0.05 & RI, MS, Co \\
\hline Camphene hydrate & $\mathrm{C}_{10} \mathrm{H}_{18} \mathrm{O}$ & 1152 & 0.16 & - & RI, MS \\
\hline Borneol & $\mathrm{C}_{10} \mathrm{H}_{18} \mathrm{O}$ & 1159 & 0.38 & - & RI, MS \\
\hline Benzenepropanal & $\mathrm{C}_{9} \mathrm{H}_{10} \mathrm{O}$ & 1167 & - & 7.42 & RI, MS \\
\hline Terpinen-4-ol & $\mathrm{C}_{10} \mathrm{H}_{18} \mathrm{O}$ & 1177 & 1.4 & - & RI, MS, Co \\
\hline$\alpha$-Terpineol & $\mathrm{C}_{10} \mathrm{H}_{18} \mathrm{O}$ & 1191 & 9.85 & 0.68 & RI, MS, Co \\
\hline Benzylacetone & $\mathrm{C}_{10} \mathrm{H}_{12} \mathrm{O}$ & 1211 & 0.53 & 26.77 & RI, MS \\
\hline Fenchyl acetate & $\mathrm{C}_{12} \mathrm{H}_{20} \mathrm{O}_{2}$ & 1218 & 0.55 & - & RI, MS \\
\hline Nonanoic acid & $\mathrm{C}_{9} \mathrm{H}_{18} \mathrm{O}_{2}$ & 1283 & - & 0.35 & RI, MS \\
\hline$\alpha$-Cubebene & $\mathrm{C}_{15} \mathrm{H}_{24}$ & 1352 & 0.50 & - & RI, MS \\
\hline$\alpha$-Terpinyl acetate & $\mathrm{C}_{12} \mathrm{H}_{20} \mathrm{O}_{2}$ & 1360 & - & 0.24 & RI, MS \\
\hline$\alpha$-Copaene & $\mathrm{C}_{15} \mathrm{H}_{24}$ & 1372 & 0.45 & - & RI, MS \\
\hline Isoledene & $\mathrm{C}_{15} \mathrm{H}_{24}$ & 1375 & 0.38 & - & RI, MS \\
\hline$\beta$-Elemene & $\mathrm{C}_{15} \mathrm{H}_{24}$ & 1388 & 0.37 & - & RI, MS \\
\hline$\alpha$-Bergamotene & $\mathrm{C}_{15} \mathrm{H}_{24}$ & 1410 & - & 0.56 & RI, MS \\
\hline$\alpha$-Santalol & $\mathrm{C}_{15} \mathrm{H}_{24} \mathrm{O}$ & 1417 & - & 0.34 & RI, MS \\
\hline$\beta$-Caryophyllene & $\mathrm{C}_{15} \mathrm{H}_{24}$ & 1420 & 0.44 & 0.07 & RI, MS \\
\hline Undecanoic acid & $\mathrm{C}_{11} \mathrm{H}_{22} \mathrm{O}_{2}$ & 1441 & - & 0.27 & RI, MS \\
\hline$\alpha$-Humulene & $\mathrm{C}_{15} \mathrm{H}_{24}$ & 1455 & 0.13 & - & RI, MS, Co \\
\hline Alloaromadendrene & $\mathrm{C}_{15} \mathrm{H}_{24}$ & 1463 & - & 0.12 & RI, MS \\
\hline$\beta$-Patchoulene & $\mathrm{C}_{15} \mathrm{H}_{24}$ & 1465 & 0.41 & - & RI, MS \\
\hline Germacrene D & $\mathrm{C}_{15} \mathrm{H}_{24}$ & 1480 & 1.13 & - & RI, MS \\
\hline$\beta$-Selinene & $\mathrm{C}_{15} \mathrm{H}_{24}$ & 1485 & 0.14 & 0.05 & RI, MS \\
\hline Valencene & $\mathrm{C}_{15} \mathrm{H}_{24}$ & 1489 & - & 0.09 & RI, MS \\
\hline$\alpha$-Selinene & $\mathrm{C}_{15} \mathrm{H}_{24}$ & 1492 & 1.62 & 0.05 & RI, MS \\
\hline$\alpha$-Muurolene & $\mathrm{C}_{15} \mathrm{H}_{24}$ & 1497 & 0.34 & - & RI, MS \\
\hline Zingiberene & $\mathrm{C}_{15} \mathrm{H}_{24}$ & 1498 & 1.05 & - & RI, MS, Co \\
\hline Calamenene & $\mathrm{C}_{15} \mathrm{H}_{22}$ & 1504 & 0.42 & - & RI, MS \\
\hline$\delta$-Cadinene isomers & $\mathrm{C}_{15} \mathrm{H}_{24}$ & 1523 & 5.44 & 0.42 & RI, MS \\
\hline Guaiacylacetone & $\mathrm{C}_{10} \mathrm{H}_{12} \mathrm{O}_{3}$ & 1528 & - & 10.13 & RI, MS \\
\hline Viridiflorol & $\mathrm{C}_{15} \mathrm{H}_{26} \mathrm{O}$ & 1588 & - & 1.42 & RI, MS \\
\hline$\tau$-Muurolol & $\mathrm{C}_{15} \mathrm{H}_{26} \mathrm{O}$ & 1643 & - & 0.04 & RI, MS \\
\hline$\beta$-Eudesmol & $\mathrm{C}_{15} \mathrm{H}_{26} \mathrm{O}$ & 1648 & - & 0.03 & RI, MS \\
\hline$\alpha$-Cadinol & $\mathrm{C}_{15} \mathrm{H}_{26} \mathrm{O}$ & 1654 & 0.65 & - & RI, MS \\
\hline$Z$ - $\alpha$-trans-Bergamotol & $\mathrm{C}_{15} \mathrm{H}_{24} \mathrm{O}$ & 1685 & - & 0.18 & RI, MS \\
\hline Aristolone & $\mathrm{C}_{15} \mathrm{H}_{22} \mathrm{O}$ & 1765 & - & 0.05 & RI, MS \\
\hline 1,7-Diphenyl-5-hydroxy-3-heptanone & $\mathrm{C}_{19} \mathrm{H}_{20} \mathrm{O}$ & 1785 & - & 17.68 & RI, MS \\
\hline 3-Phenylbutanol & $\mathrm{C}_{10} \mathrm{H}_{14} \mathrm{O}$ & 1789 & - & 0.35 & RI, MS \\
\hline Monoterpenoids & & & 81.84 & 9.69 & \\
\hline Sesquiterpenoids & & & 13.47 & 3.42 & \\
\hline Total & & & 96.39 & 68.90 & \\
\hline
\end{tabular}

${ }^{a}$ RI, retention index of the chromatography determined on a HP-5MS column using the homologous series of $n$-alkanes as reference. ${ }^{b}$ The retested data were about the same with our previous results [17]. ${ }^{\mathrm{c}}$ Identification method: RI, comparison of retention indices with published data; MS, comparison of mass spectra with those listed in the NIST 05 and Wiley 275 libraries and with published data; Co, co-injection with standard compound. 


\subsection{Structure Elucidation}

From the data in Table 1, it was found that nearly $30 \%$ of the compounds were not identified by GC-MS; this may be because those compounds were thermally decomposed by the heating process in testing [21]. Thus, this study tried to isolate the compounds from the SFE extracts of $A$. officinarum rhizomes. Finally, one new (3) and five known (1-2, 4-6) compounds were obtained; their molecular structures are given in Figure 1. The assignment of the ${ }^{1} \mathrm{H}$ - and ${ }^{13} \mathrm{C}$-NMR signals of new compounds are listed below in 3.6. Identification of the Compounds. The new compounds were illustrated by mass spectra and NMR spectra, including ${ }^{1} \mathrm{H}$ spectroscopy, ${ }^{13} \mathrm{C}$ spectroscopy, ${ }^{1} \mathrm{H}-{ }^{1} \mathrm{H}$ correlation spectroscopy (COSY), heteronuclear single quantum coherence (HSQC), and heteronuclear multiple-bond correlation (HMBC). HRESI-MS and NMR data relating to the new compound (3) is available in Figures S1-S6. By matching with the corresponding data $\left({ }^{1} \mathrm{H}\right.$ - and ${ }^{13} \mathrm{C}-\mathrm{NMR}$ data) in literatures [24-26], the five known compounds were determined to be 5-hydroxy-1,7-diphenyl-3-heptanone (1), 1,7-diphenyl-4-hepten-3-one (2), galangin (4), galangin-3-methyl ether (5), and pinocembrin (6).<smiles>O=C(CCc1ccccc1)CC(O)CCc1ccccc1</smiles>

1<smiles>O=C(/C=C/CCc1ccccc1)CCc1ccccc1</smiles>

2<smiles>C/C=C(/C)CC(CCc1ccc(OC)c(O)c1)C(C/C=C(/C)C=CCC=C(C)F)C(=O)CCc1ccccc1</smiles>

3<smiles>[R]c1c(-c2ccccc2)oc2cc(O)cc(O)c2c1=O</smiles><smiles>O=C1CC(c2ccccc2)Oc2cc(O)cc(O)c21</smiles>

Figure 1. Compounds isolated from A. officinarum rhizomes extracted by supercritical fluid $\mathrm{CO}_{2}$ extraction (SFE).

Compound 3 isolated as a colorless needle crystals was determined as $\mathrm{C}_{35} \mathrm{H}_{48} \mathrm{O}_{3}$ by HR-ESI-MS at $m / z 515.3470[\mathrm{M}-\mathrm{H}]^{-}$(calcd. for $\mathrm{C}_{35} \mathrm{H}_{47} \mathrm{O}_{3}, 515.3525$ ). The ${ }^{1} \mathrm{H}-\mathrm{NMR}$ and ${ }^{13} \mathrm{C}-\mathrm{NMR}$ spectroscopic data of compound 3 were very similar to those of diarylheptanoids skeleton [24-26]. In the ${ }^{1} \mathrm{H}-\mathrm{NMR}$ spectrum, the presence of the phenolic hydroxyl group was supported by active hydrogen. One signal at $\delta 5.45(1 \mathrm{H}, \mathrm{s})$, and the methoxy group signal was at $\delta 3.90(3 \mathrm{H}, \mathrm{s})$. The remainder of the spectrum consisted of two sets of signals systems. One set of signals appeared at $\delta 7.23\left(2 \mathrm{H}, \mathrm{d}, J=7.3 \mathrm{~Hz}, \mathrm{H}-2^{\prime}, 6^{\prime}\right)$, $\delta 7.16\left(3 \mathrm{H}, \mathrm{t}, J=6.5 \mathrm{~Hz}, \mathrm{H}-3^{\prime}, 4^{\prime}, 5^{\prime}\right)$ and another at $\delta 6.82\left(1 \mathrm{H}, \mathrm{d}, J=8.0 \mathrm{~Hz}, \mathrm{H}-5^{\prime \prime}\right), \delta 6.70\left(1 \mathrm{H}, \mathrm{s}, \mathrm{H}-2^{\prime \prime}\right), \delta$ $6.65\left(1 \mathrm{H}, \mathrm{d}, J=8.0 \mathrm{~Hz}, \mathrm{H}-6^{\prime \prime}\right)$. Instead of the olefinic proton at $\delta 5.33(1 \mathrm{H}, \mathrm{s}, \mathrm{H}-20), \delta 4.97(1 \mathrm{H}, \mathrm{t}, J=7.0 \mathrm{~Hz}$, $\mathrm{H}-9)$ and $\delta 5.08(1 \mathrm{H}, \mathrm{t}, J=7.0 \mathrm{~Hz}, \mathrm{H}-13)$, the ${ }^{1} \mathrm{H}-\mathrm{NMR}$ spectrum showed signals for five methyl singlet protons observed at $\delta 1.72(3 \mathrm{H}, \mathrm{s}, \mathrm{H}-22), \delta 1.66(3 \mathrm{H}, \mathrm{s}, \mathrm{H}-17), \delta 1.58(3 \mathrm{H}, \mathrm{s}, \mathrm{H}-15), \delta 1.53(3 \mathrm{H}, \mathrm{s}, \mathrm{H}-16)$ and $\delta 1.27(3 \mathrm{H}, \mathrm{s}, \mathrm{H}-21)$. The ${ }^{13} \mathrm{C}$ spectrum showed the presence of 35 carbons, including one carbonyl 
carbon at $\delta 211.3(\mathrm{C}-3)$, six olefin carbons at $\delta 120.7$ (C-20), $\delta 123.8(\mathrm{C}-9), \delta 124.5(\mathrm{C}-13), \delta 131.5(\mathrm{C}-14), \delta$ 135.9 (C-10), $\delta 136.3$ (C-19), five methyl carbons at $\delta 16.3$ (C-16), $\delta 17.8$ (C-15), $\delta 25.9(\mathrm{C}-17), \delta 29.6$ (C-21), $\delta 22.9(\mathrm{C}-22)$, and one methoxyl carbon at $\delta 56.1\left(-\mathrm{OCH}_{3}\right)$. The signal assignment of 2D-NMR spectra was carried out and is shown in Figure 2. The COSY spectrum exhibited the correlations between H-6 $(\delta$ $1.80)$ and H-7 ( $\delta 2.51)$, and H-4 ( $\delta 2.63)$ and H-8 ( $\delta 2.24)$. The HMBC spectrum indicated that $\delta 6.65(1 H$, $\left.\mathrm{d}, J=8.0 \mathrm{~Hz}, \mathrm{H}-6^{\prime \prime}\right)$ has correlation with 32.9 (C-7), $114.3\left(\mathrm{C}-5^{\prime \prime}\right)$ and $146.5\left(\mathrm{C}-4^{\prime \prime}\right) ; \delta 6.82(1 \mathrm{H}, \mathrm{d}, J=8.0 \mathrm{~Hz}$, H-5") has correlation with 111.1 (C-6"), 134.5 (C-1"), 146.5 (C-4") and 143.7 (C-3"); $\delta 6.70\left(1 \mathrm{H}, \mathrm{s}, \mathrm{H}-2^{\prime \prime}\right)$ has correlation with 134.5 (C-1"), $32.9(\mathrm{C}-7), 146.5\left(\mathrm{C}-4^{\prime \prime}\right)$ and $143.7\left(\mathrm{C}-3^{\prime \prime}\right) ; \delta 5.08(1 \mathrm{H}, \mathrm{t}, J=7.0 \mathrm{~Hz}, \mathrm{H}-13)$ has correlation with 25.9 (C-17),17.8 (C-15) and $40.1(\mathrm{C}-11) ; \delta 4.97(1 \mathrm{H}, \mathrm{t}, J=7.0 \mathrm{~Hz}, \mathrm{H}-9)$ has correlation with 40.1 (C-11), 16.3 (C-10) and 28.7 (C-8); $\delta 5.33$ (1H, s, H-20) has correlation with 29.6 (C-21), 22.9 (C-22) and $41.2(\mathrm{C}-5) ; \delta 2.63(1 \mathrm{H}, \mathrm{dd}, J=4.5,10.0 \mathrm{~Hz}, \mathrm{H}-4)$ has correlation with $30.1(\mathrm{C}-8), 211.3(\mathrm{C}-3)$, 36.5 (C-6), 41.2 (C-5), 28.7 (C-8), 44.9 (C-2) and 135.9 (C-10); $\delta 7.23$ (2H, d, J = $\left.7.31 \mathrm{~Hz}, \mathrm{H}-2^{\prime}, 6^{\prime}\right)$ has correlation with $29.8(\mathrm{C}-1), 141.5\left(\mathrm{C}-1^{\prime}\right)$ and $128.5\left(\mathrm{C}-2^{\prime}, 6^{\prime}\right) ; \delta 2.24(2 \mathrm{H}, \mathrm{dd}, J=5.9,11.0 \mathrm{~Hz}, \mathrm{H}-8)$ has correlation with 28.7 (C-8), 123.8 (C-9), 55.5 (C-4), 211.3 (C-3), 120.7 (C-20), 22.9 (C-22) and 136.3 (C-19). In addition, the quaternary carbons of 4" and 3" (146.5 and 143.7 ppm, respectively) suggested the existence of substituent group. In inductive effect, the $-\mathrm{OCH}_{3}$ is a withdrawing electron group stronger than $-\mathrm{OH}$, which leads to the increasing ${ }^{13} \mathrm{C}$ chemical shift, so the $-\mathrm{OCH}_{3}$ was contacted to 4 " while $-\mathrm{OH}$ was jointed at $3^{\prime \prime}$. On the basis of these results, the structure of compound 3 was identified as 1-phenyl-4-(16,17-dimethyl-9,13-octadiene)-5-isopentenyl-7-(4"'-methoxyl-3"'-hydroxyl-phenyl) -3-heptanone.

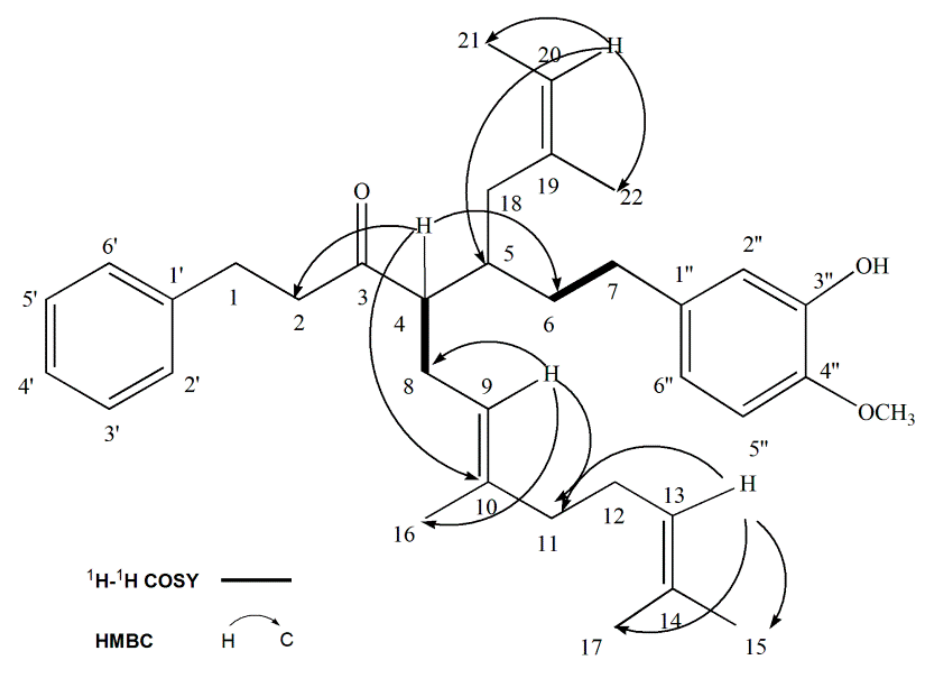

Figure 2. ${ }^{1} \mathrm{H}-{ }^{1} \mathrm{H}$ COSY and key HMBC correlation of compound 3.

\subsection{Contact Toxicity}

In Table 2, the essential oil and SFE extracts of $A$. officinarum exhibited contact toxicity against T. castaneum adults with $\mathrm{LD}_{50}$ values of $20.71 \mu \mathrm{g} /$ adult and $82.72 \mu \mathrm{g} /$ adult, respectively. Obviously, the essential oil exhibited much stronger contact toxicity against $T$. castaneum adults than that of SFE-sample, while much less contact toxicity than the positive control, pyrethrins $(0.26 \mu \mathrm{g} / \mathrm{adult})$. Compared with SFE-sample (9.69\%), the higher contact toxicity of the essential oil (81.84\%) might be attributed to the high content of monoterpenoids. They often play a key role in contact toxicities: for example, 1,8-cineole ( $\left.\mathrm{LD}_{50}=18.83 \mu \mathrm{g} / \mathrm{adult}\right)$ and terpinen-4-ol $\left(\mathrm{LD}_{50}=19.67 \mu \mathrm{g} / \mathrm{adult}\right)$ exhibited strong contact toxicity against $T$. castaneum $[27,28]$. From this perspective, it would be better to use essential oil than SFE extracts to control T. castaneum. 
Table 2. Contact toxicity of two samples from A. officinarum rhizomes.

\begin{tabular}{ccccc}
\hline Samples & LD $_{\mathbf{5 0}}(\boldsymbol{\mu g} /$ Adult $)$ & $\mathbf{9 5 \%}$ Fiducial Limits & Slope \pm SE & Chisquare $\left(\chi^{\mathbf{2}}\right)$ \\
\hline Essential Oil & 20.71 & $2.96-35.85$ & $1.39 \pm 0.41$ & 14.22 \\
SEF-sample & 82.72 & $62.28-100.29$ & $1.49 \pm 0.28$ & 10.13 \\
Pyrethrins * & 0.26 & $0.22-0.30$ & $3.34 \pm 0.32$ & 13.11 \\
\hline
\end{tabular}

* Data from You et al. [29].

\subsection{Feeding Deterrent of the Isolated Compounds}

The results of feeding deterrent activity of six compounds-5-hydroxy-1,7-diphenyl-3-heptanone (1), 1,7-diphenyl-4-hepten-3-one (2), 1-phenyl-4-(16,17-dimethyl-9,13-octadiene)-5-isopentenyl-7-(4" methoxyl-3"-hydroxyl-phenyl)-3-heptanone (3), galangin (4), galangin-3-methyl ether (5), and pinocembrin (6)-isolated from SFE-sample of A. officinarum rhizome are shown in Table 3. All the isolated compounds showed mild feeding deterrent activity against $T$. castaneum adults. With the increase of concentration, their effects enhanced gradually. At $1500 \mathrm{ppm}$ concentrations, compound 6 (pinocembrin) exhibited the highest feeding deterrent activity among six isolated compounds. In previous research, galangin showed feeding deterrent activity on Epiphyas postvittana [30]. It was also found that pinocembrin presents feeding deterrent activity against Epilachna paenulata and Spodoptera frugiperda [31,32]. This study found feeding deterrent activity from pinocembrin $(35.81 \%$, at 1500 ppm concentrations) against $T$. castaneum adults. Compared with other testing concentrations (15-500 ppm), the new compound 3 exhibited relative feeding deterrent activity at highest testing concentrations (1500 ppm). The compounds from SFE extracts also have potential to prevent feeding by this insect. Further research will concentrate on more feeding deterrent activity constituents from A. officinarum.

Table 3. Feeding deterrent activity of six compounds isolated from SFE-sample of A. officinarum rhizomes against $T$. castaneum adults.

\begin{tabular}{|c|c|c|c|c|c|}
\hline \multirow{3}{*}{ Compounds } & \multicolumn{5}{|c|}{ Feeding Deterrent Indices (\%) (Mean \pm SD) } \\
\hline & \multicolumn{5}{|c|}{ Concentration * $(\mathrm{ppm})$} \\
\hline & 15 & 50 & 150 & 500 & 1500 \\
\hline 1 & $14.56 \pm 1.12$ & $15.16 \pm 1.05$ & $16.24 \pm 0.68$ & $16.50 \pm 3.15$ & $18.21 \pm 2.71$ \\
\hline 2 & $1.13 \pm 0.98$ & $6.29 \pm 1.25$ & $9.33 \pm 0.88$ & $18.09 \pm 1.59$ & $18.94 \pm 1.38$ \\
\hline 3 & $12.78 \pm 1.30$ & $13.91 \pm 1.81$ & $19.12 \pm 2.80$ & $19.68 \pm 2.75$ & $19.79 \pm 2.62$ \\
\hline 4 & $15.98 \pm 2.20$ & $18.10 \pm 1.39$ & $19.72 \pm 0.75$ & $23.79 \pm 2.23$ & $26.99 \pm 1.27$ \\
\hline 5 & $12.84 \pm 2.79$ & $13.67 \pm 0.82$ & $14.48 \pm 1.07$ & $15.68 \pm 1.51$ & $20.34 \pm 0.78$ \\
\hline 6 & $10.38 \pm 1.75$ & $12.60 \pm 1.07$ & $16.09 \pm 2.18$ & $19.94 \pm 1.32$ & $35.81 \pm 2.24$ \\
\hline
\end{tabular}

\section{Materials and Methods}

\subsection{Chemicals}

$n$-Hydrocarbons $\left(\mathrm{C}_{5}-\mathrm{C}_{36}\right)$ were purchased from Sigma-Aldrich (St. Louis, MO, USA). All other chemicals and reagents were of analytical grade.

\subsection{Plant Material}

A. officinarum rhizomes were collected from Zhanjiang City, Guangdong, China (20.33 $\mathrm{N}$ latitude; $110.17^{\circ}$ E longitude). The plant was identified by Dr. Liu, Q.R. (College of Life Science, Beijing Normal University, Beijing, China). A voucher specimen (BNU-CMH-Dushushan-2013-06-11-014) was deposited at the Herbarium of College of Resources Science and Technology in Beijing Normal University. 


\subsection{Extraction and Isolation}

A. officinarum rhizomes $(10 \mathrm{~kg})$ were extracted at $50{ }^{\circ} \mathrm{C}, 5-6 \mathrm{Mpa}$, and $30 \mathrm{~L} / \mathrm{h}$ of $\mathrm{CO}_{2}$ flow on HA321-50-16 instrument, for 2.5 h to get SFE-sample. Anhydrous sodium sulphate was used to remove extra water from extraction. The essential oil sample was from previous research [17]. The two samples were stored in airtight containers in a refrigerator at $4{ }^{\circ} \mathrm{C}$ for further analysis.

The SFE-sample (30.0 g) was chromatographed on a silica-gel $\left(\mathrm{SiO}_{2}, 50 \mathrm{~mm}\right.$ i.d., $600 \mathrm{~mm}$ length, 160 to 200 mesh, Qingdao Marine Chemical Plant, Qingdao, Shandong Province, China) by gradient elution with petroleum ether first, then with petroleum ether-ethyl acetate, and finally with ethyl acetate to obtain 20 fractions. The fractions were further purified on silica gel columns until the pure compounds were obtained. Finally, five pure compounds were obtained from fraction 2 and fraction 6. With the monitoring of thin-layer chromatography (TLC, precoated silica gel G plates, Qingdao Marine Chemical Plant, Qingdao, Shandong, China), fraction 2 was eluted with PE-EtOAc 30/1 on silica gel, then further purified by a Sephadex LH-20 column (Pharmacia, Sweden) and recrystallized to get compound $\mathbf{1}$ (2267.2 mg, Figure 1) and 2 (23.6 mg, Figure 1). Fraction 6 was re-chromatographed on silica gel and eluted with PE-EtOAc, and then on a Sephadex LH-20 column (Pharmacia, Sweden) with methanol to yield compound 3 (17.6 mg, Figure 1), 4 (450.1 mg, Figure 1), 5 (19.0 mg, Figure 1) and 6 (388.0 mg, Figure 1). The molecular structures of the isolated compounds were elucidated based on the analysis of ${ }^{1} \mathrm{H}$ - and ${ }^{13} \mathrm{C}-\mathrm{NMR}$ spectra, which were recorded on an Avance III NMR spectrometer (Bruker-Biospin, Billerica, MA, USA).

\subsection{Insects}

Examples of the red flour beetle T. castaneum used in the following screening for the test were obtained from laboratory cultures for the last three years in a dark incubator at $28-30{ }^{\circ} \mathrm{C}$, with $70-80 \%$ relative humidity. The insects were reared in glass containers $(0.5 \mathrm{~L})$ containing wheat flour at $12-13 \%$ moisture content mixed with yeast (wheatfeed/yeast, 10:1, w/w). Adults used in the experiments were about two weeks old.

\subsection{GC-MS and GC-FID Analyses}

The two samples of A. officinarum were analyzed using a Thermo Finnigan Trace DSQ GC/MS instrument (Thermo Finnigan, Lutz, FL, USA) equipped with a flame ionization detector (FID) and a HP-5MS $(30 \mathrm{~m} \times 0.25 \mathrm{~mm} \times 0.25 \mu \mathrm{m})$ capillary column. The mass spectrometer was performed in the electron-impact mode, with ionization energy of $70 \mathrm{eV}$ in $\mathrm{m} / \mathrm{e}$ at a range of 10-550 amu. The same column and analysis were used in both GC-FID and GC-MS analysis. The temperature was programmed isothermal at $50{ }^{\circ} \mathrm{C}$ for $2 \mathrm{~min}$, then rising from 50 to $150{ }^{\circ} \mathrm{C}$ at the speed of $2{ }^{\circ} \mathrm{C} / \mathrm{min}$, then held isothermal for $2 \mathrm{~min}$ at $150{ }^{\circ} \mathrm{C}$, rising from 150 to $250{ }^{\circ} \mathrm{C}$ at the speed of $10{ }^{\circ} \mathrm{C} / \mathrm{min}$, and finally held isothermal at $250{ }^{\circ} \mathrm{C}$ for $5 \mathrm{~min}$. The injector temperature was $250^{\circ} \mathrm{C}$, and the flow rate of helium (the carrier gas) was $1.0 \mathrm{~mL} / \mathrm{min}$. The samples were diluted ( $1 \%$ solution, $v / v$, diluted in $n$-hexane) and then manually injected in the split mode. Constituents of the two samples were identified by comparing their retention indices (RIs), which were determined to the retention times of a series of $n$-alkanes $\left(\mathrm{C}_{5}-\mathrm{C}_{36}\right)$ or with those reported in the literature [33]. Quantification was determined by percentage peak area calculations using GC-FID, while, the major constituents were identified by being coinjected with standards and confirmed by using the National Institute of Standards and Technology (NIST) version 05 GC-MS libraries (Standard Reference Data, Gaithersburg, MD, USA) and Wiley 275 mass-spectral libraries (Wiley, New York, NY, USA) or in the literature [34].

\subsection{Identification of the Compounds}

Chemical structures were assigned by analysis of the MS, ${ }^{1} \mathrm{H},{ }^{13} \mathrm{C}$ and $2 \mathrm{D}-\mathrm{NMR}$ spectra and comparison with literature values. Accordingly, compounds 1-6 were identified as 5-hydroxy-1,7diphenyl-3-heptanone [24,25], 1,7-diphenylhept-4-en-3-heptanone [26], 1-phenyl-4-(16,17-dimethyl- 
9,13-octadiene)-5-isopentenyl-7-(4"-hydroxyl-3"-methoxyl-phenyl)-3-heptanone, galangin [26], galangin-3-methyl ether [26], and pinocembrin [26], respectively (Figure 1).

5-Hydroxy-1,7-diphenyl-3-heptanone (1). $\mathrm{C}_{19} \mathrm{H}_{22} \mathrm{O}_{2}$, colorless needles. ESI-MS $m / z: 283.1[\mathrm{M}+\mathrm{H}]^{+}$. ${ }^{1} \mathrm{H}-\mathrm{NMR}\left(500 \mathrm{MHz}, \mathrm{CDCl}_{3}\right)$ 8ppm: $7.29\left(4 \mathrm{H}, \mathrm{m}, \mathrm{H}-2^{\prime}, 6^{\prime}, 2^{\prime \prime}, 6^{\prime \prime}\right), 7.20\left(6 \mathrm{H}, \mathrm{m}, \mathrm{H}-3^{\prime}, 4^{\prime}, 5^{\prime}, 3^{\prime \prime}, 4^{\prime \prime}, 5^{\prime \prime}\right)$, $4.06(1 \mathrm{H}, \mathrm{dq}, J=12.3,4.0 \mathrm{~Hz}, \mathrm{H}-5), 3.87(1 \mathrm{H}, \mathrm{br} \mathrm{s}, \mathrm{OH}), 2.91(2 \mathrm{H}, \mathrm{t}, J=7.6 \mathrm{~Hz}, \mathrm{H}-1), 2.81(1 \mathrm{H}, \mathrm{m}, \mathrm{H}-2)$, $2.76(2 \mathrm{H}, \mathrm{dd}, J=13.6,5.9 \mathrm{~Hz}, \mathrm{H}-4), 2.68(1 \mathrm{H}, \mathrm{ddd}, J=13.8,9.3,7.1 \mathrm{~Hz}, \mathrm{H}-2), 2.55(2 \mathrm{H}, \mathrm{m}, \mathrm{H}-7), 1.81$ $(1 \mathrm{H}, \mathrm{ddd}, J=14.2,8.8,4.5 \mathrm{~Hz}, \mathrm{H}-6), 1.68(1 \mathrm{H}, \mathrm{m}, \mathrm{H}-6) ;{ }^{13} \mathrm{C}-\mathrm{NMR}\left(125 \mathrm{MHz}, \mathrm{CDCl}_{3}\right) \delta \mathrm{ppm}: 211.2(\mathrm{C}-3)$, $141.9\left(\mathrm{C}-1^{\prime}\right), 140.8\left(\mathrm{C}-1^{\prime \prime}\right), 128.7\left(\mathrm{C}-3^{\prime}, 5^{\prime}\right), 128.6\left(\mathrm{C}-3^{\prime \prime}, 5^{\prime \prime}\right), 128.5\left(\mathrm{C}-2^{\prime \prime}, 6^{\prime \prime}\right), 128.4\left(\mathrm{C}-2^{\prime}, 6^{\prime}\right), 126.3\left(\mathrm{C}-4^{\prime}\right)$, 126.0 (C-4"), 67.0 (C-5), 49.4 (C-4), 45.1 (C-2), 38.1 (C-6), 31.8 (C-1), 29.6 (C-7).

1,7-Diphenyl-4-hepten-3-one (2). $\mathrm{C}_{19} \mathrm{H}_{20} \mathrm{O}$, colorless needles. ESI-MS $m / z: 265.1[\mathrm{M}+\mathrm{H}]^{+} .{ }^{1} \mathrm{H}-\mathrm{NMR}$ $\left(500 \mathrm{MHz}, \mathrm{CDCl}_{3}\right) \delta$ ppm: $7.29\left(4 \mathrm{H}, \mathrm{m}, \mathrm{H}-3^{\prime}, 5^{\prime}, 3^{\prime \prime}, 5^{\prime \prime}\right), 7.19\left(6 \mathrm{H}, \mathrm{m}, \mathrm{H}-2^{\prime}, 4^{\prime}, 6^{\prime}, 2^{\prime \prime}, 4^{\prime \prime}, 6^{\prime \prime}\right), 6.84(1 \mathrm{H}, \mathrm{dt}$, $J=6.8,15.9 \mathrm{~Hz}, \mathrm{H}-5), 6.11(1 \mathrm{H}, \mathrm{d}, J=15.9 \mathrm{~Hz}, \mathrm{H}-4), 2.93(2 \mathrm{H}, \mathrm{t}, J=7.0 \mathrm{~Hz}, \mathrm{H}-2), 2.84(2 \mathrm{H}, \mathrm{dd}, J=4.4$, $11.2 \mathrm{~Hz}, \mathrm{H}-1), 2.77(2 \mathrm{H}, \mathrm{t}, J=7.7 \mathrm{~Hz}, \mathrm{H}-7), 2.53(2 \mathrm{H}, \mathrm{q}, J=7.1 \mathrm{~Hz}, \mathrm{H}-6) ;{ }^{13} \mathrm{C}-\mathrm{NMR}\left(125 \mathrm{MHz}, \mathrm{CDCl}_{3}\right) \delta$ ppm: 199.6 (C-3), 146.5 (C-5), $141.4\left(\mathrm{C}-1^{\prime}\right), 140.8$ (C-1") 130.9 (C-4), 128.7 (C-3', 5'), 128.5 (C-2', 6'), 128.6 (C-3", 5"), $128.5\left(\mathrm{C}-2^{\prime \prime}, 6^{\prime \prime}\right), 126.4\left(\mathrm{C}-4^{\prime}\right), 126.2\left(\mathrm{C}-4^{\prime \prime}\right), 41.9$ (C-2), 34.3 (C-6), 34.6 (C-7), 30.2 (C-1).

1-Phenyl-4-(16,17-dimethyl-9,13-octadiene)-5-isopentenyl-7-(4"-methoxyl-3"-hydroxyl-phenyl)-3-heptanone (3). $\mathrm{C}_{35} \mathrm{H}_{48} \mathrm{O}_{3}$, colorless needles, HRESI-MS m/z: $515.3470[\mathrm{M}-\mathrm{H}]^{+} .{ }^{1} \mathrm{H}-\mathrm{NMR}\left(500 \mathrm{MHz}, \mathrm{CDCl}_{3}\right) \delta$ ppm: $7.23\left(2 \mathrm{H}, \mathrm{d}, J=7.3 \mathrm{~Hz}, \mathrm{H}-2^{\prime}, 6^{\prime}\right), 7.16\left(3 \mathrm{H}, \mathrm{t}, J=6.5 \mathrm{~Hz}, \mathrm{H}-3^{\prime}, 4^{\prime}, 5^{\prime}\right), 6.82\left(1 \mathrm{H}, \mathrm{d}, \mathrm{J}=8.0 \mathrm{~Hz}, \mathrm{H}-5^{\prime \prime}\right)$, $6.70\left(1 \mathrm{H}, \mathrm{s}, \mathrm{H}-2^{\prime \prime}\right), 6.65\left(1 \mathrm{H}, \mathrm{d}, \mathrm{J}=8.0 \mathrm{~Hz}, \mathrm{H}-6^{\prime \prime}\right), 5.45\left(1 \mathrm{H}, \mathrm{s}, 4^{\prime \prime}-\mathrm{OH}\right), 5.33(1 \mathrm{H}, \mathrm{s}, \mathrm{H}-20), 5.08(1 \mathrm{H}, \mathrm{t}, J=$ $7.0 \mathrm{~Hz}, \mathrm{H}-13), 4.97(1 \mathrm{H}, \mathrm{t}, J=7.0 \mathrm{~Hz}, \mathrm{H}-9), 3.90\left(3 \mathrm{H}, \mathrm{s}, 3^{\prime \prime}-\mathrm{OCH}_{3}\right), 2.83(2 \mathrm{H}, \mathrm{m}, \mathrm{H}-1), 2.78(2 \mathrm{H}, \mathrm{m}, \mathrm{H}-2)$, $2.63(1 \mathrm{H}, \mathrm{dd}, J=4.5,10.0 \mathrm{~Hz}, \mathrm{H}-4), 2.51(2 \mathrm{H}, \mathrm{ddd}, J=5.5,10.5,16.5 \mathrm{~Hz}, \mathrm{H}-7), 2.24(2 \mathrm{H}, \mathrm{dd}, J=5.9,11.0$ Hz, H-8), 2.06 (5H, m, H-18), 1.96 (1H, m, H-11), 1.80 (1H, m, H-6), 1.72 (3H, s, H-22), 1.66 (3H, s, H-17), $1.58(3 \mathrm{H}, \mathrm{s}, \mathrm{H}-15), 1.53$ (3H, s, H-16), 1.27 (3H, s, H-21); ${ }^{13} \mathrm{C}-\mathrm{NMR}\left(125 \mathrm{MHz}, \mathrm{CDCl}_{3}\right) \delta$ ppm: 211.3 (C-3), 146.5 (C-4"), 143.7 (C-3"), 141.5 (C-1'), 136.3 (C-19), 135.9 (C-10), 134.5 (C-1"), 131.5 (C-14), 128.6 (C-3', 5'), 128.5 (C-2', 6'), 126.1 (C-4'), 124.5 (C-13), 123.8 (C-9), 121.0 (C-2"'), 120.7 (C-20), 114.3 (C-5"), 111.1 (C-6"), $56.1\left(3^{\prime \prime}-\mathrm{OCH}_{3}\right), 55.5$ (C-4), 44.9 (C-2), 41.2 (C-5), 40.1 (C-11), 36.6 (C-12), 36.5 (C-6), 32.9 (C-7), 30.1 (C-8), 29.8 (C-1), 29.6 (C-21), 28.7 (C-8), 26.8 (C-12), 25.9 (C-17), 22.9 (C-22), 17.8 (C-15), 16.3 (C-16).

Galangin (4). $\mathrm{C}_{15} \mathrm{H}_{10} \mathrm{O}_{3}$, yellow needles. ESI-MS $m / z: 269.0[\mathrm{M}-\mathrm{H}]^{-} .{ }^{1} \mathrm{H}-\mathrm{NMR}$ (500 MHz, DMSO- $d_{6}$ ) $\delta$ ppm: $12.36(1 \mathrm{H}, \mathrm{s}, 5-\mathrm{OH}), 10.86(1 \mathrm{H}, \mathrm{s}, 7-\mathrm{OH}), 9.67(1 \mathrm{H}, \mathrm{s}, 3-\mathrm{OH}), 8.15\left(2 \mathrm{H}, \mathrm{d}, J=7.8 \mathrm{~Hz}, \mathrm{H}-2^{\prime}, 6^{\prime}\right), 7.55$ $\left(2 \mathrm{H}, \mathrm{t}, J=7.5 \mathrm{~Hz}, \mathrm{H}-3^{\prime}, 5^{\prime}\right), 7.50\left(1 \mathrm{H}, \mathrm{t}, J=7.2 \mathrm{~Hz}, \mathrm{H}-4^{\prime}\right), 6.47(1 \mathrm{H}, \mathrm{s}, \mathrm{H}-8), 6.21(1 \mathrm{H}, \mathrm{s}, \mathrm{H}-6) ;{ }^{13} \mathrm{C}-\mathrm{NMR}$ (125 MHz, DMSO-d $d_{6}$ ) $\delta$ ppm: 177.7 (C-4), 165.9 (C-7), 162.7 (C-9), 158.5 (C-10), 147.0 (C-1'), 138.5 (C-2), $132.7\left(\mathrm{C}-3^{\prime}, 5^{\prime}\right), 128.8$ (C-3), 130.9 (C-4'), $129.5\left(\mathrm{C}-2^{\prime}, 6^{\prime}\right), 104.7$ (C-10), 99.4 (C-6), 94.5 (C-8).

Galangin-3-methyl ether (5). $\mathrm{C}_{16} \mathrm{H}_{12} \mathrm{O}_{3}$, yellow powder. ESI-MS $m / z: 283.0[\mathrm{M}-\mathrm{H}]^{-} .{ }^{1} \mathrm{H}-\mathrm{NMR}$ (500 MHz, DMSO- $\left.d_{6}\right) \delta$ ppm: $12.57(1 \mathrm{H}, \mathrm{s}, 5-\mathrm{OH}), 10.92(1 \mathrm{H}, \mathrm{s}, 7-\mathrm{OH}), 8.01(2 \mathrm{H}, \mathrm{dd}, J=3.0,6.6 \mathrm{~Hz}$, H-2', 6'), $7.58\left(3 \mathrm{H}, \mathrm{m}, \mathrm{H}-3^{\prime}, 4^{\prime}, 5^{\prime}\right), 6.47(1 \mathrm{H}, \mathrm{d}, J=2.0 \mathrm{~Hz}, \mathrm{H}-8), 6.23(1 \mathrm{H}, \mathrm{d}, J=1.9 \mathrm{~Hz}, \mathrm{H}-6), 3.81(3 \mathrm{H}, \mathrm{s}$, 3-OCH 3 ); ${ }^{13} \mathrm{C}-\mathrm{NMR}\left(125 \mathrm{MHz}\right.$, DMSO- $\left.d_{6}\right) \delta$ ppm: 178.1 (C-4), 164.4 (C-7), 161.3 (C-5), 156.6 (C-9), 155.2 (C-2), 138.8 (C-3), 131.1 (C-4'), 130.1 (C-1'), 128.8 (C-3', 5'), 128.2 (C-2', 6'), 104.5 (C-10), 98.7 (C-6), 93.9 (C-8), $60.0\left(3-\mathrm{OCH}_{3}\right)$.

Pinocembrin (6). $\mathrm{C}_{15} \mathrm{H}_{12} \mathrm{O}_{2}$, white needles. ESI-MS $m / z$ : $255.0[\mathrm{M}-\mathrm{H}]^{-} .{ }^{1} \mathrm{H}-\mathrm{NMR}$ (500 MHz, DMSO- $d_{6}$ ) $\delta$ ppm: $12.13(1 \mathrm{H}, \mathrm{s}, 5-\mathrm{OH}), 10.82(1 \mathrm{H}, \mathrm{s}, 7-\mathrm{OH}), 7.52\left(2 \mathrm{H}, \mathrm{d}, J=7.5 \mathrm{~Hz}, \mathrm{H}-2^{\prime}, 6^{\prime}\right), 7.41(3 \mathrm{H}, \mathrm{dt}, J=7.2$, $\left.23.3 \mathrm{~Hz}, \mathrm{H}-3^{\prime}, 4^{\prime}, 5^{\prime}\right), 5.91(2 \mathrm{H}, \mathrm{m}, \mathrm{H}-6,8), 5.59(1 \mathrm{H}, \mathrm{dd}, J=2.9,12.7 \mathrm{~Hz}, \mathrm{H}-2), 3.26(1 \mathrm{H}, \mathrm{dd}, J=12.7,17.1$ $\mathrm{Hz}, \mathrm{H}-3 \alpha), 2.78(1 \mathrm{H}, \mathrm{dd}, J=2.9,17.1 \mathrm{~Hz}, \mathrm{H}-3 \beta) ;{ }^{13} \mathrm{C}-\mathrm{NMR}\left(125 \mathrm{MHz}, \mathrm{DMSO}-d_{6}\right) \delta$ ppm: $196.0(\mathrm{C}-4)$, 166.7 (C-7), 163.5 (C-9), 162.7 (C-5), 138.7 (C-1'), 128.5 (C-3', 4', 5'), 126.6 (C-2', 6'), 101.8 (C-10), 95.9 (C-6), 95.0 (C-8), 78.4 (C-2), 42.1 (C-3). 


\subsection{Contact Toxicity}

The contact toxicity of two samples against $T$. castaneum adults was measured as described by Liu and Ho [35]. Previous studies were run to find range and determine the appropriate testing concentrations. The serial dilutions of the oil extracts were prepared in $n$-hexane. Aliquots of $0.5 \mu \mathrm{L}$ of the dilutions were applied topically to the dorsal thorax of the insects. Controls were determined using $n$-hexane. Both treated and control insects were then transferred to glass vials ( 10 insects per vial, five replicates per dose) with feed and kept in incubators. Mortality percentages were recorded after $24 \mathrm{~h}$ of the treatment and the $\mathrm{LD}_{50}$ values were calculated using Probit analysis [36].

\subsection{Feeding Deterrent Bioassay}

A flour-disk bioassay was used to evaluate the feeding deterrent activities of six isolated compounds from rhizomes of A. officinarum following the method of Xieal et al. [37] with some modification [35,38-40]. The test solutions $(1 \mathrm{mg} / \mathrm{mL})$ were prepared with pure compounds dissolved in ethanol. Serials of even flour-water suspensions $(2 \mathrm{~mL})$ were prepared with $0.4 \mathrm{~g}$ wheat flour, different volumes of the testing solutions, and distilled water. Aliquots $(200 \mu \mathrm{L})$ of this ultrasonically stirred suspension were placed on the bottom of a polystyrene Petri dish to form disks. About 1 $\mathrm{cm}$ was cut from the bottom of a disposable tip with a razor blade to make an opening enlarged to about $2 \mathrm{~mm}$ in diameter to make appropriate flour disks. The same amounts of ethanol and distilled water were applied to form the control flour disks. The flour disks were air-dried in the fume-hood overnight. Then, all flour-disks were transferred to an incubator to equilibrate at $28-30{ }^{\circ} \mathrm{C}$ and $70-80 \%$ R.H. for $48 \mathrm{~h}$. The moisture content of each disk was controlled to be $13.5 \pm 0.1 \%$ using the Kett's Grain moisture tester (Model PB-1D2, Tokyo, Japan). The flour disks were placed in glass vials (diameter $2.5 \mathrm{~cm}$, height $5.5 \mathrm{~cm}$ ) for weighing. Twenty groups were weighed, and then unsexed insects were added to each vial prior for further weighing. All the testing insects were starved for $24 \mathrm{~h}$ before use. After that, all the experimental set-up was placed in the incubator for three days. Finally, all the tested insects were picked out and the uneaten parts of the flour disks were weighed. Compared to the control group, the insect consumption for the different test samples was calculated. The percentage feeding deterrent index was calculated from the following equation:

$$
\text { Feeding deterrent index }=[(C-T) / C] \times 100 \%
$$

where $C$ is the weight of diet consumed in control and $T$ is the weight of diet consumed in the treatment. Five replicates of each concentration of each compound and control were done for the test.

\section{Conclusions}

This work compared the chemical composition of two samples of A. officinarum rhizomes obtained by HD and SFE method and their contact toxicity on T. castaneum adults. The different toxicity attributed to their various chemical constitutes. Extraction methods must be selected according to the functional requirements of products. One new compound (3) together with five known compounds (1-2, 4-6) was isolated from the SFE sample. All the isolated compounds exhibited mild feeding deterrent activities against $T$. castaneum adults (15-1500 ppm). The new compound showed feeding deterrent activities (19.79\%) at $1500 \mathrm{ppm}$. Compound $\mathbf{6}$ (pinocembrin) had strong feeding deterrent activities (35.81\%) against T. castaneum at the concentration of $1500 \mathrm{ppm}$. These results showed that the essential oil and SFE extracts/compounds of A. officinarum rhizomes are an alternative in the control of stored-product insects. They also provided significant information for the development and comprehensive utilization of $A$. officinarum. 
Supplementary Materials: Supplementary materials are available online. HRESI-MS and NMR data relating to the new compound (3) is available in Figure S1-S6.

Acknowledgments: This project was supported by the National Key Research and Development Program (2016YFC0500805), the Fundamental Research Funds for the Central Universities, and the Beijing Municipal Foundation for the Central Universities.

Author Contributions: Mintong Xin and Shushan Du were responsible for the experimental design; Shanshan Guo was responsible for the determination of insecticidal activity; Zhufeng Geng and Junyu Liang performed reseach and analyzed the data; Mintong Xin and Wenjuan Zhang wrote the article; Zhiwei Deng and Yongyan Wang revised the manuscript. All authors read and approved the final manuscript.

Conflicts of Interest: The authors declare no conflict of interest.

\section{References}

1. Wijayaratne, L.K.W.; Arthur, F.H.; Whyard, S. Methoprene and control of stored-product insects. J. Stored. Prod. Res. 2016, in press. [CrossRef]

2. Buckman, K.A.; Campbell, J.F. How varying pest and trap densities affect Tribolium castaneum capture in pheromone traps. Entomol. Exp. Appl. 2013, 146, 404-412. [CrossRef]

3. Liu, Z.L.; Cao, J.; Zhang, H.M.; Lin, L.L.; Du, S.S.; Zhou, L.G.; Deng, Z.W. Feeding deterrents from Aconitum episcopale roots against the red flour beetle, Tribolium castaneum. J. Agric. Food Chem. 2011, 59, 3701-3706. [CrossRef] [PubMed]

4. You, C.X.; Wang, Y.; Zhang, W.J.; Yang, K.; Wu, Y.; Geng, Z.F.; Chen, H.P.; Jiang, H.Y.; Du, S.S.; Deng, Z.W.; et al. Chemical constituents and biological activities of the Purple Perilla essential oil against Lasioderma serricorne. Ind. Crop Prod. 2014, 61, 331-337. [CrossRef]

5. Zettler, J.L.; Arthur, F.H. Chemical control of stored product insects with fumigants and residual treatments. Crop Prot. 2000, 19, 577-582. [CrossRef]

6. Copping, L.G.; Menn, J.J. Biopesticides: A review of their action, applications and efficacy. Pest Manag. Sci. 2000, 8, 651-676. [CrossRef]

7. Isman, M.B. Botanical insecticides, deterrents, and repellents in modern agriculture and an increasingly regulated world. Annu. Rev. Entomol. 2006, 51, 45-66. [CrossRef] [PubMed]

8. Ding, W.; Liu, H.; Li, L.S. The main stratagems and technology for stored product pest control in ancient China. J. Southwest Agric. Univ. 2000, 22, 335-338.

9. Yang, K.; You, C.X.; Wang, C.F.; Guo, S.S.; Li, Y.P.; Wu, Y.; Geng, Z.F.; Deng, Z.W.; Du, S.S. Composition and repellency of the essential oils of Evodia calcicola Chun ex Huang and Evodia trichotoma (Lour.) Pierre against three stored product insects. J. Oleo Sci. 2014, 63, 1169-1176. [CrossRef] [PubMed]

10. Wang, C.F.; Yang, K.; You, C.X.; Zhang, W.J.; Guo, S.S.; Geng, Z.F.; Du, S.S.; Wang, Y.Y. Chemical composition and insecticidal activity of essential oils from Zanthoxylum dissitum leaves and roots against three species of storage pests. Molecules 2015, 20, 7990-7999. [CrossRef] [PubMed]

11. Zou, Q.Y.; Wu, H.F.; Tang, Y.L.; Chen, D.Z. A new labdane diterpene from the rhizomes of Alpinia officinarum. Nat. Prod. Res. 2016, 30, 1-6. [CrossRef] [PubMed]

12. Lin, L.Y.; Peng, C.C.; Yeh, X.Y.; Huang, B.Y.; Wang, H.E.; Chen, K.C.; Peng, R.Y. Antihyperlipidemic bioactivity of Alpinia officinarum (Hance) Farw Zingiberaceae can be attributed to the coexistance of curcumin, polyphenolics, dietary fibers and phytosterols. Food Funct. 2015, 6, 1600-1610. [CrossRef] [PubMed]

13. Li, H.F.; Li, Y.H.; Wang, Y.; Wei, N.; Tan, Y.F.; Zhang, J.Q. Advances in studies on chemical constituents in Alpiniae officinarum rhizoma and their pharmacological activities. Chin. J. Exp. Tradit. Med. Form. 2014, 20, 236-244.

14. Liu, C.N. Antagonistic storage method of traditional Chinese medicinal material. J. Chin. Med. Mater. 1987, 4, 36. [CrossRef]

15. Liu, Z.L.; Goh, S.H.; Ho, S.H. Screening of Chinese medicinal herbs for bioactivity against Sitophilus zeamais Motschulsky and Tribolium castaneum (Herbst). J. Stored Prod. Res. 2007, 43, 290-296. [CrossRef]

16. Zhao, N.N.; Zhou, L.G.; Liu, Z.L.; Du, S.S.; Deng, Z.W. Evaluation of the toxicity of the essential oils of some common Chinese spices against Liposcelis bostrychophila. Food Control 2012, 26, 486-490. [CrossRef]

17. Wu, Y.; Wang, Y.; Li, Z.H.; Wang, C.F.; Wei, J.Y.; Li, X.L.; Wang, P.J.; Zhou, Z.F.; Du, S.S.; Huang, D.Y.; et al. Composition of the essential oil from Alpinia galanga rhizomes and its bioactivity on Lasioderma serricorne. Bull. Insectol. 2014, 67, 247-254. 
18. Abdullah, F.; Subramanian, P.; Ibrahim, H.; Malek, S.N.A.; Lee, G.S.; Hong, S.L. Chemical composition, antifeedant, repellent, and toxicity activities of the rhizomes of galangal, Alpinia galanga against Asian subterranean termites, Coptotermes gestroi and Coptotermes curvignathus (Isoptera: Rhinotermitidae). J. Insect Sci. 2015, 15, 7. [CrossRef] [PubMed]

19. Conde-Hernández, L.A.; Espinosa-Victoria, J.R.; Trejo, A.; Guerrero-Beltrán, J.A. $\mathrm{CO}_{2}$-supercritical extraction, hydrodistillation and steam distillation of essential oil of rosemary (Rosmarinus officinalis). J. Food Eng. 2017, 200, 81-86. [CrossRef]

20. Garcia-Perez, J.S.; Robledo-Padilla, F.; Cuellar-Bermudez, S.P.; Parra-Saldivar, R.; Zavala-Yoe, R.; Ramirez-Mendoza, R.A.; Iqbal, H.M.N. Thermodynamics and statistical correlation between supercritical- $\mathrm{CO}_{2}$, fluid extraction and bioactivity profile of locally available mexican plants extracts. J. Supercrit. Fluid 2017, 122, 27-34. [CrossRef]

21. Luo, J.; Rui, W.; Jiang, M.; Tian, Q.; Ji, X.; Feng, Y. Separation and identification of diarylheptanoids in supercritical fluid extract of Alpinia officinarum by UPLC-MS-MS. J. Chromatogr. Sci. 2010, 48, 795-801. [CrossRef] [PubMed]

22. Sunarso, J.; Ismadji, S. Decontamination of hazardous substances from solid matrices and liquids using supercritical fluids extraction: A review. J. Hazard. Mater. 2009, 161, 1-20. [CrossRef] [PubMed]

23. Pang, Q.H.; He, J.H.; Zeng, R.J.; Zhao, S.J. Comparison of volatile oil in Alpinia officinarum Hance extracted by different methods. Pharm. Biotechnol. 2008, 15, 54-58.

24. Hema, P.S.; Nair, M.S. Flavonoids and other constituents from the rhizomes of Alpinia calcarata. Biochem. Syst. Ecol. 2009, 37, 52-54. [CrossRef]

25. Pulkkinen, J.T.; Honkakoski, P.; Peräkylä, M.; Berczi, I.; Laatikainen, R. Synthesis and evaluation of estrogen agonism of diaryl 4,5-dihydroisoxazoles, 3-hydroxyketones, 3-methoxyketones, and 1,3-diketones: A compound set forming a 4d molecular library. J. Med. Chem. 2008, 1, 3562-3571. [CrossRef] [PubMed]

26. An, N.; Yang, S.L.; Zhou, Z.M.; Xu, L.Z. Flavonoids of Alpinia officinarum. Chin. Tradit. Herb. Drugs 2006, 5, 663-664.

27. Zhang, W.J.; Yang, K.; You, C.X.; Wang, Y.; Wang, C.F.; Wu, Y.; Geng, Z.F.; Su, Y.; Du, S.S.; Deng, Z.W. Bioactivity of essential oil from Artemisia stolonifera (Maxim.) Komar. and its main compounds against two stored-product insects. J. Oleo Sci. 2015, 64, 299-307. [CrossRef] [PubMed]

28. Zhang, W.J.; Yang, K.; You, C.X.; Wang, C.F.; Geng, Z.F.; Su, Y.; Wang, Y.; Du, S.S.; Deng, Z.W. Contact toxicity and repellency of the essential oil from Mentha haplocalyx Briq.against Lasioderma serricorne. Chem. Biodivers. 2015, 12, 832-839. [CrossRef] [PubMed]

29. You, C.X.; Yang, K.; Wu, Y.; Zhang, W.J.; Wang, Y.; Geng, Z.F.; Chen, H.P.; Jiang, H.Y.; Du, S.S.; Deng, Z.W.; et al. Chemical composition and insecticidal activities of the essential oil of Perilla frutescens (L.) Britt. aerial parts against two stored product insects. Eur. Food Res. Technol. 2014, 239, 481-490. [CrossRef]

30. Russell, G.B.; Bowers, W.S.; Keesing, V.; Niemeyer, H.M.; Sevenet, T.; Vasanthaverni, S.; Wratten, S.D. Patterns of bioactivity and herbivory on Nothofagus species from Chile and New Zealand. J. Chem. Ecol. 2000, 26, 41-56. [CrossRef]

31. Napal, G.N.D.; Defagó, M.T.; Valladares, G.R.; Sara, M.P. Response of Epilachna paenulata to two flavonoids, pinocembrin and quercetin, in a comparative study. J. Chem. Ecol. 2010, 36, 898-904. [CrossRef] [PubMed]

32. Georgina, N.; Napal, D.; Carpinella, M.C.; Palacios, S.M. Antifeedant activity of ethanolic extract from Flourensia oolepis and isolation of pinocembrin as its active principle compound. Bioresour. Technol. 2009, 100, 3669-3673.

33. Huang, A.; Sefton, M.A.; Taylor, D.K. Comparison of the formation of peppery and woody sesquiterpenes derived from $\alpha$-guaiene and $\alpha$-bulnesene under aerial oxidative conditions. J. Agric. Food Chem. 2015, 63, 1932-1938. [CrossRef] [PubMed]

34. Adam, R.P. Identification of essential oil components by gas chromatography/quadrupole mass spectroscopy. J. Am. Soc. Mass Spectrom. 2001, 16, 1902-1903.

35. Liu, Z.L.; Ho, S.H. Bioactivity of the essential oil extracted from Evodia rutaecarpa Hook f. et Thomas against the grain storage insects, Sitophilus zeamais Motsch. and Tribolium castaneum (Herbst). J. Stored Prod. Res. 1999, 35, 317-328. [CrossRef]

36. Sakuma, M. Probit analysis of preference data. Appl. Entomol. Zool. 1998, 339-347.

37. Xieal, Y.S.; Bodnarykal, R.P.; Fieldsal, P.G. A rapid and simple flour-disk bioassay for testing substance active against stored-product insects. Can. Entomol. 1996, 5, 865-875. 
38. Du, S.S.; Wang, C.F.; Li, J.; Zhang, H.M.; Liu, Q.Z.; Liu, Z.L.; Deng, Z.W. Antifeedant diterpenoids against Tribolium castaneum from the stems and twigs of Ceriops tagal (Rhizophoraceae). Molecules 2011, 16, 6060-6067. [CrossRef] [PubMed]

39. Liu, Z.L.; Chu, S.S.; Jiang, G.H. Feeding Deterrents from Zanthoxylum schinifolium against two stored-product insects. J. Agric. Food Chem. 2009, 57, 10130-10133. [CrossRef] [PubMed]

40. Wang, C.F.; You, C.X.; Yang, K.; Guo, S.S.; Geng, Z.F.; Fan, L.; Du, S.S.; Deng, Z.W.; Wang, Y. Antifeedant activities of methanol extracts of four Zanthoxylum species and benzophenanthridines from stem bark of Zanthoxylum schinifolium against Tribolium castaneum. Ind. Crop. Prod. 2015, 74, 407-411. [CrossRef]

Sample Availability: Samples of the compounds are available from the authors.

(C) 2017 by the authors. Licensee MDPI, Basel, Switzerland. This article is an open access article distributed under the terms and conditions of the Creative Commons Attribution (CC BY) license (http:/ / creativecommons.org/licenses/by/4.0/). 